\title{
Urbanização, dispersão das cidades e aglomeração urbana: um olhar sobre as cidades médias
}

\author{
Urbanización, dispersión urbana y aglomeración urbana: una \\ mirada sobre las ciudades medias
}

\section{Urbanization, urban sprawl, and urban agglomeration: a perspective about the middle-sized cities}

\author{
Cleverson Alexsander Reolon \\ careolon@uem.br \\ Universidade Estadual de Maringá, UEM, Maringá, PR \\ Vitor Koiti Miyazaki \\ vitor.ufu@ufu.br \\ Universidade Federal de Uberlândia, UFU, Uberlândia, MG
}

Resumo: No artigo, analisa-se a conformação de aglomerações urbanas polarizadas por cidades médias, buscando-se compreender em que medida essa configuração ocorre em função do papel regional exercido por essas cidades. Do ponto de vista empírico, as interações espaciais estabelecidas entre as cidades pesquisadas são identificadas pelos deslocamentos pendulares. São analisadas as interações espaciais estabelecidas entre três cidades médias e seus respectivos entornos regionais: Itajaí, Londrina e São José do Rio Preto. Espera-se contribuir com a problematização da discussão que trata da relação entre a continuidade territorial e a continuidade espacial na perspectiva dos processos de dispersão das cidades e de aglomeração urbana.

Palavras-chave: continuidade territorial e espacial; Índice de eficácia migratória; deslocamentos pendulares.

Resumen: En el artículo se analiza la configuración de aglomeraciones urbanas polarizadas por ciudades medias, buscando comprender en qué medida esa configuración ocurre en función del papel regional ejercido por esas ciudades. Desde el punto de vista empírico, las interacciones espaciales establecidas entre las ciudades analizadas son identificadas por los desplazamientos pendulares. Se analizan las interacciones espaciales establecidas entre tres ciudades medias y sus respectivos entornos regionales: Itajaí, Londrina y São José do Rio Preto. Se espera contribuir con la problematización de la discusión que trata de la relación entre la continuidad territorial y la continuidad espacial en la perspectiva de los procesos de dispersión y de aglomeración urbana.

Palabras clave: continuidad territorial y espacial; Índice de eficacia migratoria; desplazamientos pendulares.

Abstract: This study focuses on theanalysis of the configuration of urban agglomerations polarized by middle-sized cities, searching to understand if this configuration occurs due to the regional role played by these cities. From the empirical point of view, the spatial interactions established between the researched cities are referenced 
by the commuting displacements. The spatial interactions established among three middle-sized cities and their respective regional environments are analyzed: Itajaí, Londrina and São José do Rio Preto. The intent of this discussion is to contribute to the problematization of the discussion that deals with the territorial and spatial continuity, from the perspective of the urban sprawl and the agglomeration process.

Keywords: territorial and spatial continuity; Index of migration effectiveness; commuting.

\section{INTRODUÇÃO}

Partindo-se do fato de que a cidade média é definida, entre outros aspectos, pelas funções urbanas que desempenha no contexto regional, neste artigo está pautado nos deslocamentos pendulares realizados entre diferentes municípios. Assume-se, desse modo, a prerrogativa de que deslocamentos dessa natureza desempenham importante papel na compreensão das relações entre a cidade e a região no que se refere à urbanização contemporânea.

Entende-se que os deslocamentos pendulares intermunicipais têm se tornado tão frequentes, inclusive no interior do território, que os processos de aglomeração urbana passaram a caracterizar a nova realidade da urbanização brasileira. Por essa razão o enfoque do estudo é a análise da constituição de aglomerações urbanas polarizadas por cidades médias, buscando-se compreender em que medida essas configurações ocorrem em função do papel regional exercido por essas cidades. Não se trata de processos de aglomeração urbana tais como os originados a partir das grandes metrópoles nacionais, embora o princípio teórico do processo de formação do aglomerado seja o mesmo. Mudanças de contexto em relação às práticas espaciais, dadas pela ampliação das possibilidades e distâncias de deslocamento das pessoas, mudanças nas lógicas econômicas, representadas pelo modo como as grandes empresas e os demais agentes econômicos (incluindo os agentes imobiliários) se apropriam do espaço, determinando sua produção e reprodução, resultam em aglomerações cuja morfologia se distingue em muito da morfologia clássica das aglomerações urbanas metropolitanas, caracterizadas pela continuidade do tecido urbano.

Essas mudanças de contexto não são exclusivas do interior do país, já que afetam também as metrópoles, mas os efeitos sobre a reestruturação urbana e da cidade são mais impactantes quando os vetores de tais mudanças se estabelecem sobre cidades médias, e indícios empírico-teóricos têm sugerido que essa pressuposição é ainda mais verdadeira para o caso das cidades médias localizadas nas áreas de menor densidade da rede urbana nacional (REOLON, 2012; 2013). Considerando-se as transformações socioespaciais que acometem também as cidades situadas no interior, entende-se serem relevantes estudos que contemplem os aspectos mencionados, ilustrativos da diversidade e da complexidade da atual realidade urbana brasileira.

Espera-se contribuir, portanto, com a problematização da relação entre continuidade territorial e espacial na perspectiva dos processos de dispersão da cidade e de aglomeração urbana, a partir de três cidades e seus entornos regionais: Itajaí/SC, Londrina/PR e São José do Rio Preto/SP. Reconhece-se que podem ser insuficientes para a apreensão 
da dinâmica dos deslocamentos que ocorrem em todo o país, especialmente quando se consideram realidades distintas nas formações socioespaciais da Amazônia ou Nordeste, por exemplo. Todavia, estas análises pretendem apresentar contribuições metodológicas importantes para o tema.

O texto divide-se em duas seções principais. Inicialmente, procura-se apresentar as concepções teóricas e perspectivas analíticas que embasam a abordagem dos deslocamentos pendulares, propriamente tratando dos processos de aglomeração urbana em cidades médias. A caracterização dessas aglomerações permite o estabelecimento de um diálogo a respeito das formas urbanas que as configuram, tomando-se como referências as noções de continuidade espacial e de continuidade territorial. Em seguida, sucedendo à devida abordagem dos aspectos metodológicos, apresenta-se a análise empírica das informações geográficas concernentes aos deslocamentos pendulares realizados nas regiões imediatas às cidades escolhidas como objeto de estudo.

\section{DISPERSÃO, AGLOMERAÇÃO E FORMAS URBANAS}

A intensificação da urbanização levou à uma expressiva expansão territorial das cidades, culminando na dispersão das áreas urbanas. Sobre o assunto, Smith (2000, p. 151) destaca que o "crescimento sem precedentes das cidades nos últimos séculos reflete a enorme centralização do capital e o desenvolvimento dos meios de transporte que permitiram uma crescente dispersão geográfica". Houve, portanto, condições favoráveis para a expansão e dispersão territorial das cidades.

Atualmente, para além das grandes cidades, a expansão descontínua do tecido urbano se tornou cada vez mais evidente em centros urbanos de diferentes portes. Cidades que antes eram caracterizadas por certa continuidade territorial, hoje se expandem de maneira cada vez mais descontínua no âmbito da dispersão urbana.

Sobre o assunto, Sposito (2004) destaca a contradição existente entre a concentração, no âmbito do processo de urbanização, em relação à "tendência inversa de emergência de territorialidades marcadas pela extensão das áreas urbanas, por meio de formas espaciais mais dispersas e, muitas vezes, descontínuas" (SPOSITO, 2004, p. 11). Também neste contexto, Whitacker (2007, p. 4) afirma que "Mudanças profundas na morfologia urbana denunciam um modelo de cidade que não é mais contíguo e concentrado". Complementarmente, o autor menciona que

Essa nova morfologia urbana reorganiza, de maneira aparentemente contraditória, a dispersão e a aglomeração (GOTTDIENER, 1992), numa dinâmica que cria e recria centralidades num movimento que é poli(multi)cêntrico, como apontou Lefebvre (LEFEBVRE, 1982, p. 127-8), à medida que se organiza, não apenas com muitos centros, mas também com centros de conteúdos diferenciados.

Portanto, a conformação de áreas urbanas descontínuas não se resume apenas a um fenômeno físico, pois no processo de dispersão somam-se os conteúdos e as funções 
urbanas desempenhadas no âmbito da morfologia urbana. Inclusive, por exemplo, com mudanças também na centralidade urbana, não só no âmbito da cidade como também no cenário de centros urbanos em que a dispersão das áreas urbanas para além dos limites político-administrativos resulta em processos de aglomeração urbana. A respeito deste processo, Smith (2000) afirma que:

A maioria das áreas urbanas é legalmente definida por fronteiras administrativas, mas elas só refletem por acidente a gama de relações sociais diárias. A extensão espacial da escala urbana é demarcada com muito mais precisão pela distância em que uma jornada diária ao trabalho é exequível (SMITH, 2000, p. 151).

Torna-se necessário, conforme já destacado por Ojima (2016), articular a dimensão demográfica com a dispersão urbana no que diz respeito aos deslocamentos e mobilidade da população. A ampliação da mobilidade contribuiu para mudanças na dimensão espacial, onde atividades cotidianas são realizadas frente às múltiplas centralidades no âmbito da dispersão e da aglomeração urbana, resultando numa morfologia complexa que contempla, por exemplo, uma escala intermunicipal.

No Brasil, as transformações em relação à dispersão territorial das cidades no âmbito das aglomerações urbanas são bastante relevantes. Reis (2006) apresentou características importantes sobre a dispersão urbana e as novas formas adquiridas pelo tecido urbano no aglomerado urbano constituído a partir da Região Metropolitana deSão Paulo, contemplando as regiões de Campinas, Sorocaba e Vale do Paraíba. Sposito (2004), por sua vez, foi além das áreas metropolitanas paulistas ao analisar a dispersão territorial de diferentes cidades médias do interior do estado.

As cidades médias, frente à sua importância regional, e mais ainda aquelas que têm se apresentado como lócus aos vetores da reestruturação urbana e das cidades no momento atual, passam a configurar panoramas regionais complexos em decorrência da intensificação das interações espaciais de curtas a médias distâncias, motivadas por deslocamentos pendulares da população. Em alguns casos, os processos que envolvem estas cidades incluem a configuração de aglomerações urbanas constituídas mediante continuidades territoriais e, principalmente, espaciais.

No plano regional, o termo aglomeração urbana designa a articulação de áreas urbanas de diferentes unidades político-administrativas, mediante continuidades territoriais ou espaciais. Baseando-se em Sposito (2004), continuidade territorial e continuidade espacial distinguem-se pelo fato da primeira designar um tecido urbano único, enquanto a segunda diz respeito a uma situação de proximidade relativa, condicionada por fluxos materiais, especialmente de pessoas, e imateriais.

Entende-se que a continuidade territorial do tecido urbano seria representativa da formação de aglomerações urbanas, embora não essencial, já que o fundamental consiste na continuidade espacial, dada pela intensidade das relações sociais e econômicas estabelecidas entre os centros urbanos que a compõem. Portanto, sob tal perspectiva, a aglomeração urbana seria um espaço dotado de intensas e recíprocas relações sociais e econômicas entre dois ou mais núcleos urbanos de unidades político-administrativas distintas, onde 
se pode observar o transbordamento ou a projeção da população e das atividades de uma ou mais cidades sobre as áreas adjacentes (REOLON, 2007). Assim, duas ou mais cidades podem conformar um complexo conjunto disposto em continuidade espacial, mesmo que não haja continuidade físico-territorial dos tecidos urbanos. Essa situação é comumente constatada nas áreas que estão sendo chamadas de 'não metropolitanas' ${ }^{1}$, em muitos casos designando aglomerações urbanas polarizadas por cidades médias. Esse processo está atrelado às dinâmicas que caracterizam a urbanização contemporânea, marcada não somente pelo crescimento populacional e territorial das cidades, em função da evolução das técnicas que permitem a dispersão de seus tecidos, como também pelo incremento das interações espaciais que se estabelecem ao nível da rede urbana.

Miyazaki (2013, p. 61) sintetiza a formação de espaços urbanos descontínuos territorialmente, mas contínuos espacialmente, da seguinte forma:

[... [ a reestruturação urbana e da cidade, por meio das dinâmicas e lógicas que as orientam, têm um papel relevante na (re)configuração das morfologias urbanas atuais. Hoje, mora-se cada vez mais distante dos locais de trabalho, consumo e lazer. Os sistemas de transporte e comunicação permitem essas relocalizações, gerando formas urbanas cada vez mais descontínuas, dispersas e descompactas. Têm-se assim mudanças não só restritas às formas, mas principalmente em relação aos usos e [a]os conteúdos das diferentes partes do espaço urbano que, mesmo fisicamente descontínuos, encontram-se espacialmente articulados.

Como se pode constatar pelo mapeamento das Áreas Urbanizadas do Brasil 2015 (IBGE, 2017) ${ }^{2}$, as configurações dispersas dos perímetros urbanos das regiões adjacentes às cidades médias selecionadas para análise são ilustrativas dessas formas urbanas descontínuas do ponto de vista territorial (Figs. 1, 2 e 3).

1 o termo 'não metropolitano' talvez não seja o mais ilustrativo do cenário sob estudo porque remete a um par (metropolitano - não metropolitano) que sugere comparação e hierarquização do espaço pouco adequadas ao uso nas ciências humanas, referentes a superioridade / inferioridade entre pares. Por outro lado, a rigor, falar de um 'interior' do país também não seria o mais adequado, pois dialoga com o que seria metropolitano (remetendo ao mesmo dilema recém mencionado) ou o que estaria no litoral. Portanto os termos mencionados (interior do país, metropolitano, não metropolitano) só podem ser aqui interpretados numa perspectiva relacional cuja definição se dá em função das circunstâncias empíricas da pesquisa, e não propriamente ontológicas.

2 Áreas Urbanizadas do Brasil 2015 foi publicado em 2017, mas os arquivos vetoriais correspondentes aos perímetros das concentrações urbanas com população entre 100 mil e 300 mil habitantes e acima de 300 mil habitantes só foram disponibilizados para consulta pelo IBGE em 2018. Em estudos até então a metodologia empegava o mapeamento dos setores censitários urbanos de cada município. A vantagem deste novo conjunto de dados é que a definição das áreas urbanizadas consiste na delimitação da área construída de cada município e não nos perímetros urbanos definidos pelas prefeituras municipais. 
Figura 1: Setores censitários urbanos e aglomerações urbanas da região de Itajaí, SC.
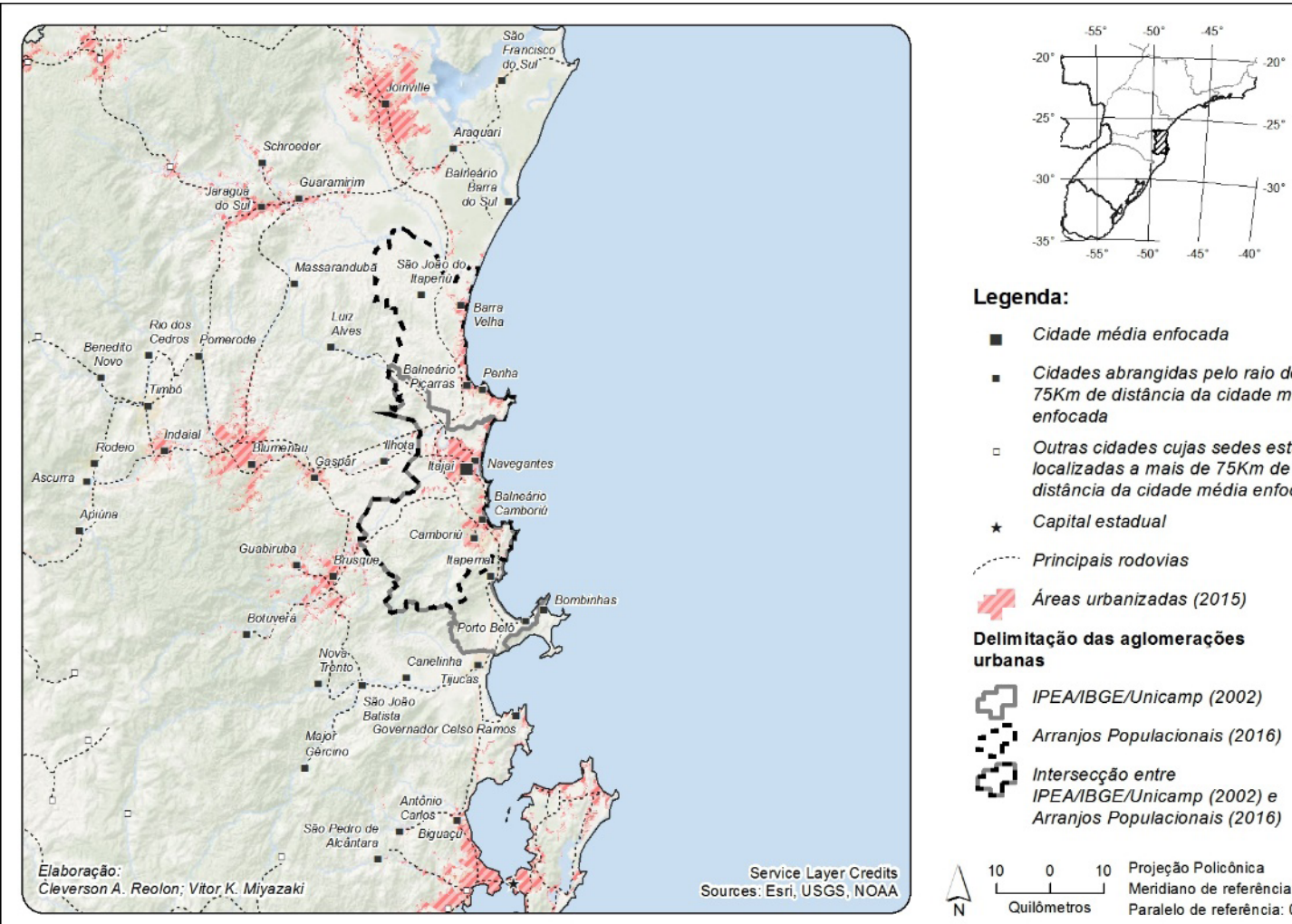

\section{Legenda:}

- Cidade média enfocada

- Cidades abrangidas pelo raio de $75 \mathrm{Km}$ de distância da cidade média enfocada

- Outras cidades cujas sedes estăo localizadas a mais de $75 \mathrm{Km}$ de distância da cidade média enfocada

$\star \quad$ Capital estadual

Principais rodovias

Áreas urbanizadas (2015)

Delimitação das aglomerações urbanas

IPEAIBGE/Unicamp (2002)

Arranjos Populacionais (2016)

Intersecção entre

IPEA/IBGE/Unicamp (2002) Arranjos Populacionais (2016)

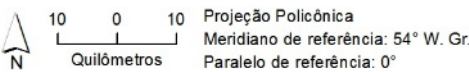

Bases e informações cartográficas: IBGE, 2015; 2017a; 2017b; IPEA, IBGE e Unicamp, 2002.

Figura 2: Setores censitários urbanos e aglomerações urbanas da região de Londrina, PR.

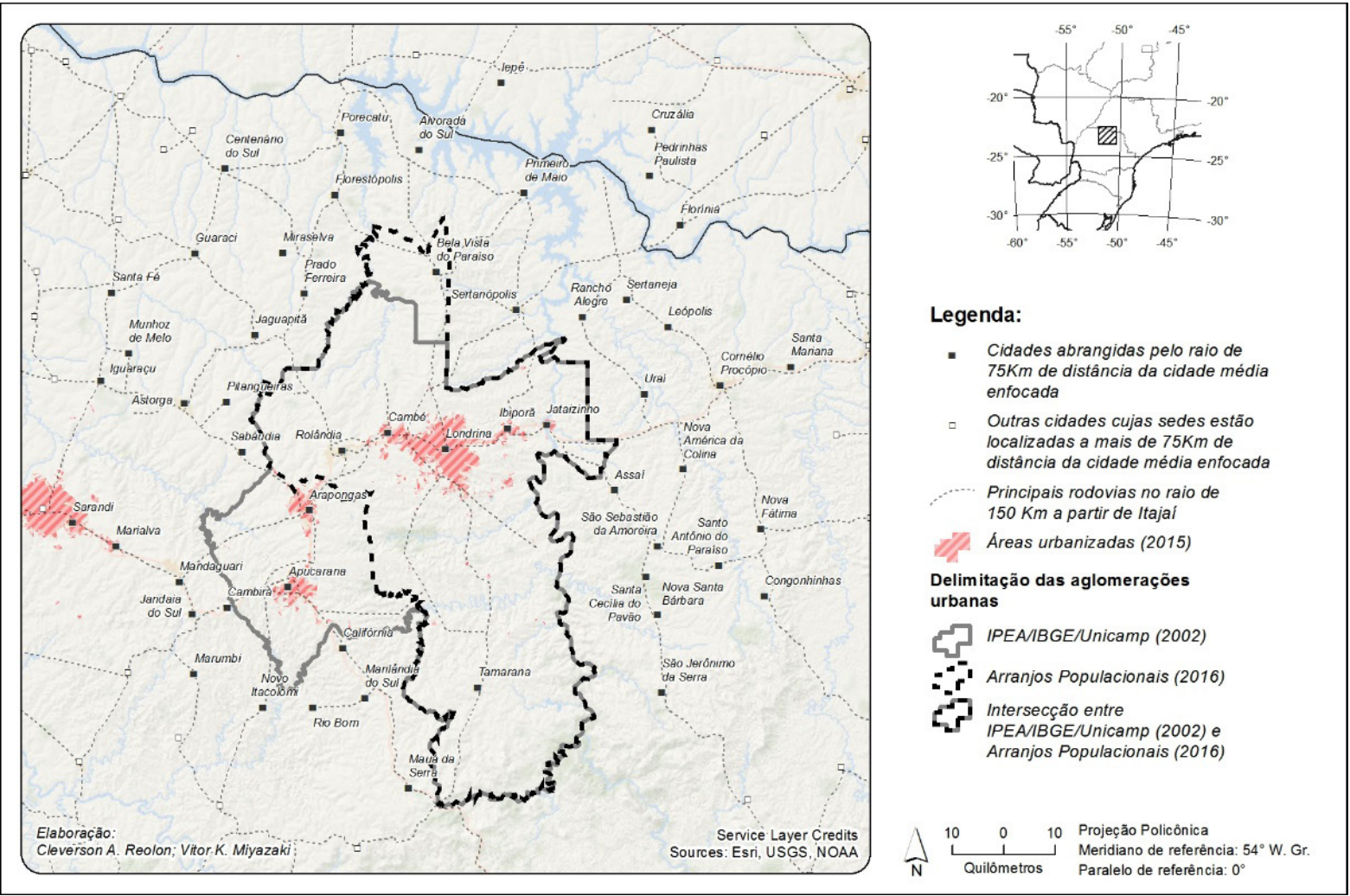

Bases e informações cartográficas: IBGE, 2015; 2017a; 2017b; IPEA, IBGE e Unicamp, 2002. 
Figura 3: Setores censitários urbanos e aglomerações urbanas da região de São José do Rio Preto, SP.

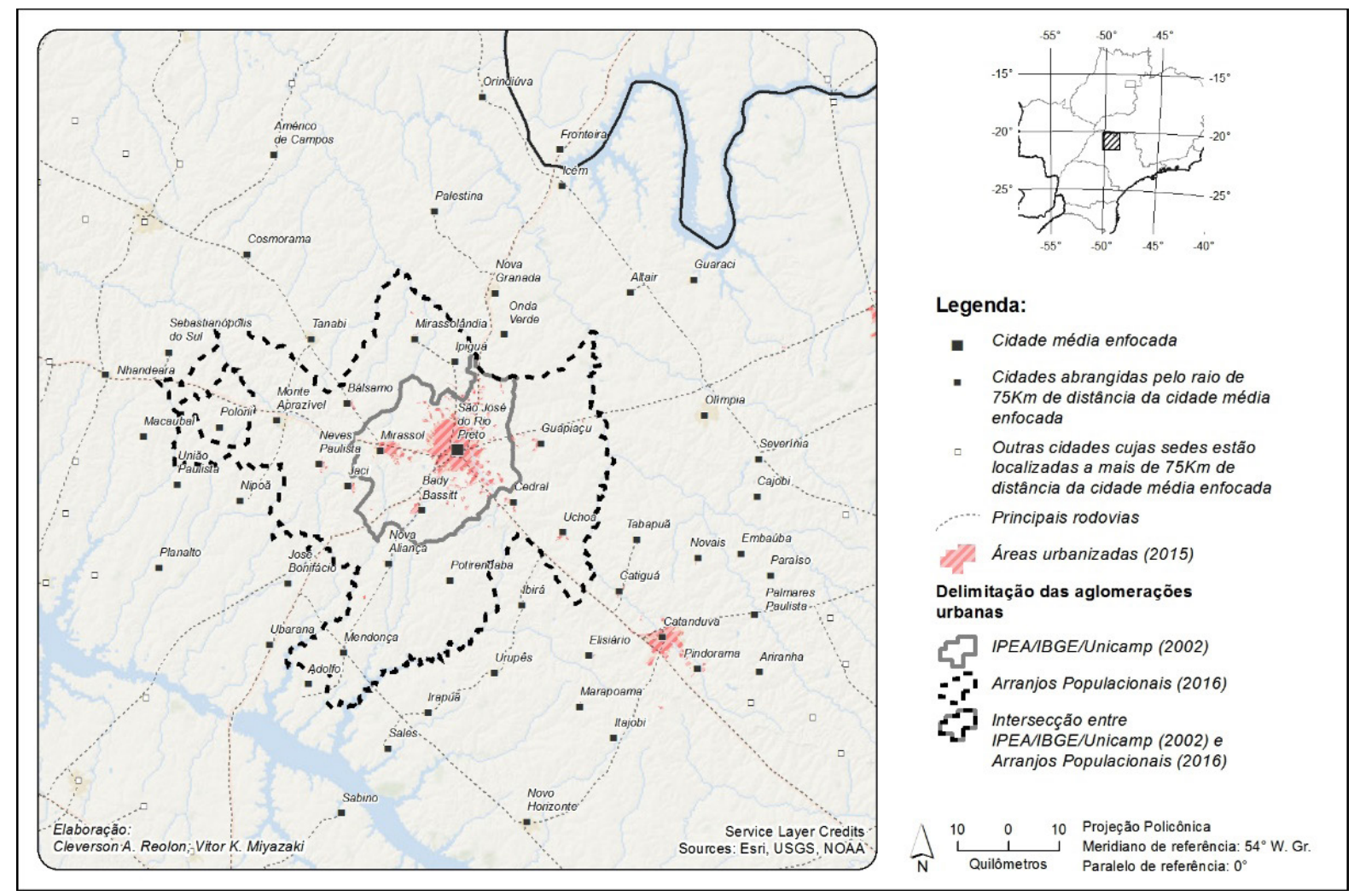

Bases e informações cartográficas: IBGE,2015; 2017a; 2017b; IPEA, IBGE e Unicamp, 2002.

A conjugação da distribuição dos perímetros das áreas urbanizadas aos aglomerados urbanos identificados pelo IPEA, IBGE e Unicamp (2002), no estudo denominado Caracterização e Tendências da Rede Urbana do Brasil, e aos arranjos populacionais urbanos identificados pelo IBGE (2016), sustentam a tese de que essas formas urbanas descontínuas estão articuladas por interações espaciais.

Em Caracterização e Tendências da Rede Urbana do Brasil as aglomerações urbanas foram mapeadas com base em critérios demográficos e econômico-estruturais, fincando de fora os critérios de integração, relativos ao deslocamento pendular exercido pela população do aglomerado, devido à ausência de informações dessa natureza (IPEA; IBGE; UNICAMP, 2001). A metodologia de identificação dos arranjos populacionais, por outro lado, foi essencialmente pautada sob critérios de integração, entendendo-se, inclusive, que a continuidade territorial das manchas urbanizadas ${ }^{3}$ situadas a distâncias inferiores a três quilômetros uma da outra fariam parte do mesmo arranjo em função das interrelações diárias supostamente subjacentes ao conjunto. Conforme o estudo, "Os critérios utilizados na identificação dos arranjos populacionais empregam a noção de integração, medida pelos movimentos pendulares para trabalho e estudo ou a contiguidade urbana, que assim sintetizam os vários processos envolvidos" (IBGE, 2016, n.p.).

3 Mancha urbanizada é designada como uma "área construída com edificações típicas de áreas urbanas e padrão de arruamento interno que propicia relações diárias de vizinhança." (IPEA; IBGE; UNICAMP, 2001). 
Não obstante, especialmente a identificação dos arranjos populacionais sejam de grande valia para a apreensão das novas realidades urbanas do país, a compreensão das dinâmicas regionais e dos papéis exercidos pelas cidades médias no âmbito desse processo demandam uma investigação mais profunda acerca das interações espaciais que se configuram nesses espaços. Por isso, a seguir analisa-se os movimentos pendulares exercidos pela população sob alguns vieses e perspectivas metodológicas que se acredita serem esclarecedoras.

\section{ANÁLISE DOS MOVIMENTOS PENDULARES}

\section{Aspectos Metodológicos}

As informações geográficas que fundamentam as análises são provenientes do IBGE, referentes aos Microdados da Amostra, disponibilizados no âmbito dos censos demográficos de 2000 e 2010. A partir dos microdados destes censos demográficos Moura, Delgado e Costa (2013) calcularam e compararam o volume de pessoas que se deslocavam entre municípios e para o exterior de cada um deles por motivo de trabalho e/ou estudo. Os autores notaram uma diferença significativa entre as entradas e saídas nos dados de 2010, em parte por conta das trocas internacionais; por se identificarem as saídas, mas não as entradas (o que também ocorre no ano de 2000); mas essencialmente por conta de uma particularidade observada:

[...] diferenciou-se a situação de pessoas que se deslocam para municípios específicos daquela em que, pela natureza da atividade, deslocam-se para vários municípios. No primeiro caso, tanto a origem como o destino são identificados. Ao se tratar de deslocamentos para vários municípios, porém, somente a origem é identificada. É por isso que o total das saídas supera o das entradas (MOURA; DELGADO; COSTA, 2013, p. 673).

Segundo os autores, na sua amostra em 2010, houve uma diferença de quase 10,9\% entre o número de pessoas que disseram deixar o município de residência por motivo de trabalho e/ou de estudo (fluxos de saída, ou de origem) em relação aos fluxos de destino, ou seja, os municípios que recebem as pessoas que realizam deslocamento pendular. Pelas razões já enunciadas, a relação origem-destino do ano de 2000 é mais equilibrada, equivalente a 5,3\% de diferença entre deslocamentos de origem e de destino. No período intercensitário, nota-se um aumento importante das pessoas que deixavam os municípios de residência para trabalhar e/ou estudar em outras localidades; no caso dos deslocamentos de origem, esse incremento foi de $98,4 \%$ e, a respeito de deslocamentos de destino, foi de $109 \%$.

Em função da metodologia proposta por Reolon e Miyazaki (2015), os recortes territoriais abrangem os municípios situados a até $75 \mathrm{Km}$ e entre 75 e $150 \mathrm{Km}$ de distância (euclidiana) das sedes das cidades médias enfocadas. O raio de $75 \mathrm{Km}$ representa uma distância propensa à realização de deslocamentos pendulares diários, ao passo que o dobro disso $(150 \mathrm{Km})$ atinge o limite dentro do qual se garante que todos os municípios situados 
nas bordas do primeiro raio sejam analisados sob os mesmos parâmetros. Os dados de deslocamentos de origem e de destino analisados neste texto não incluem as saídas para o exterior, nem aqueles cujos destinos não foram informados pelos entrevistados, ou seja, os dados dizem respeito apenas aos fluxos mapeáveis do ponto de vista geográfico (Fig. 4).

Figura 4: Recortes territoriais analisados nas três cidades médias estudadas.

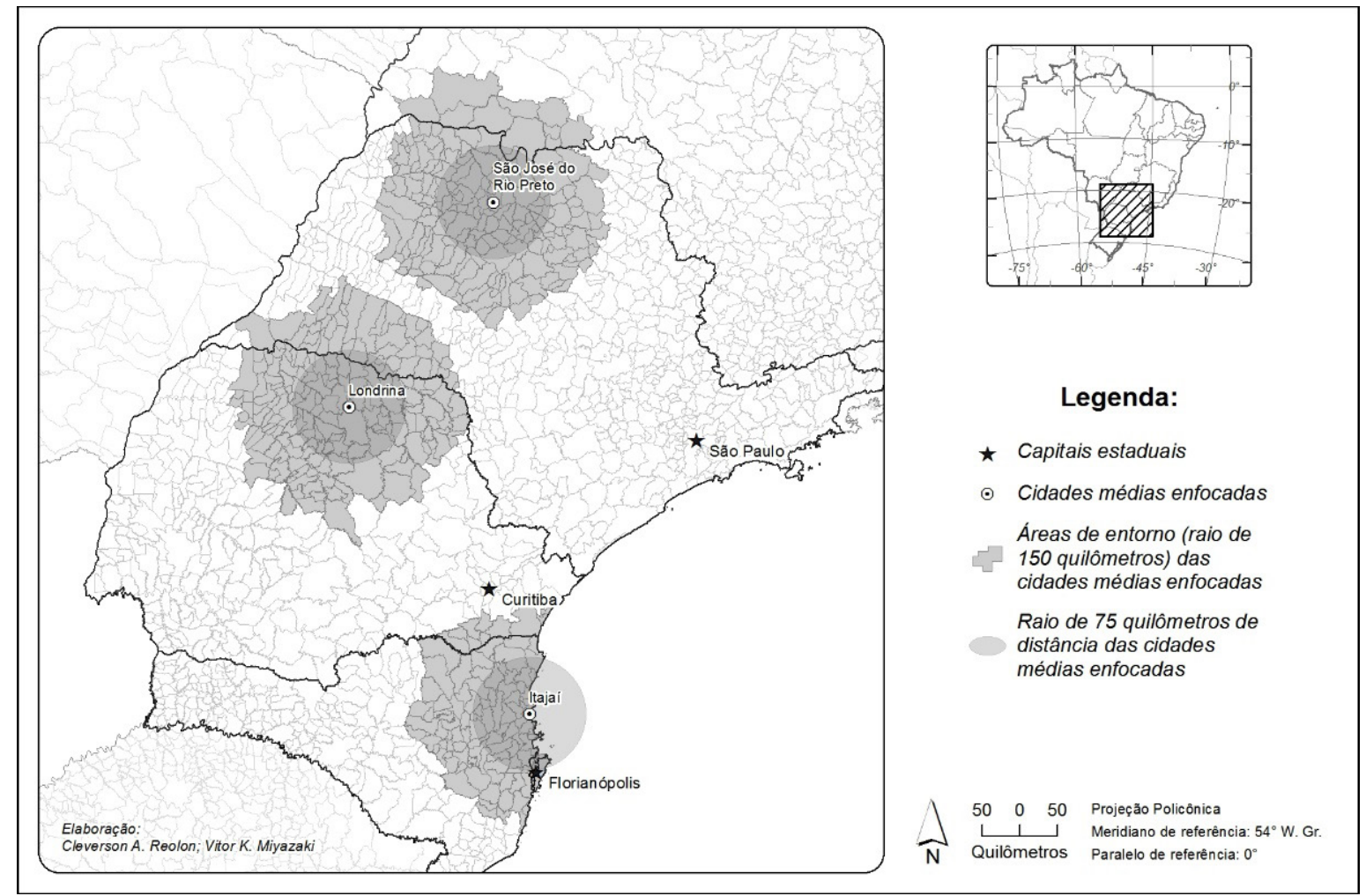

Bases cartográficas: IBGE, 2010b.

Esse caminho metodológico faz com que o montante dos deslocamentos de origem seja equivalente ao montante dos deslocamentos de destino dentro do recorte proposto para o enfoque analítico, diferindo um pouco das características do quadro geral apresentado para o Brasil. Todavia, acredita-se que isso não impossibilite traçar um paralelo entre as duas situações.

\section{Enfoque preliminar}

Totalizando-se os deslocamentos dos três recortes que correspondem ao entorno das cidades de Itajaí, de Londrina e de São José do Rio Preto, levando em consideração o raio de até $150 \mathrm{Km}$ de distância, 365.005 pessoas se deslocavam no ano de 2000 e 815.365 no ano de 2010, resultando num aumento de 123,38\% no período ${ }^{4}$. Quando o raio dos

4 devido à metodologia empregada, os montantes calculados referem-se a pessoas que se deslocam e não aos fluxos, ou seja, se uma pessoa se desloca para trabalhar e para estudar em outro município, ela é contabilizada apenas uma vez. Essa premissa permitiu a comparabilidade dos dados de deslocamento de 2000, que quantifica as pessoas que trabalham e/ou estudam, com os dados de deslocamento de 2010, cujo roteiro da entrevista identifica local de trabalho e de estudo separadamente. 
deslocamentos é alterado para $75 \mathrm{Km}$, o crescimento proporcional do volume de pessoas que trabalhava e/ou estudava em municípios diferentes da residência aumenta, embora em números absolutos a quantidade total de deslocamentos seja obviamente menor. Assim, a diferença entre 130.501 pessoas no ano de 2000 e 316.474 em 2010, resulta num aumento de $142,51 \%$.

Conforme disposto na Tabela 1, o aumento dos deslocamentos no entorno de Itajaí é superior aos verificados nos entornos de Londrina e de São José do Rio Preto, em qualquer dos raios analisados. No entanto, esse quadro comparativo, apesar de fornecer um panorama e uma ideia da dinâmica dos deslocamentos no âmbito das áreas em análise, é frágil à medida que não está ancorado num parâmetro para o estabelecimento de comparações viáveis ao entendimento das dinâmicas regionais motivadas exclusivamente em função das cidades médias enfocadas na pesquisa. Em outras palavras, pelo fato de o município de Itajaí apresentar menos da metade das populações totais de Londrina ou de São José do Rio Preto, um balanço geral dos deslocamentos sugere que a região do entorno de Itajaí é mais dinâmica do ponto de vista socioeconômico que as demais, mas não diz nada sobre a dinâmica de Itajaí em si.

Tabela 1: Quantidade de deslocamentos de origem e de destino nas três cidades analisadas em 2000 e 2010.

\begin{tabular}{|c|c|c|c|c|c|c|c|}
\hline \multirow{3}{*}{ Município } & \multirow{3}{*}{ Dist. } & \multicolumn{6}{|c|}{ Pessoas que se deslocavam } \\
\hline & & \multicolumn{3}{|c|}{ Origem } & \multicolumn{3}{|c|}{ Destino } \\
\hline & & 2000 & 2010 & $\begin{array}{c}\text { Taxa geom. } \\
\text { cresc. } \\
2000-2010\end{array}$ & 2000 & 2010 & $\begin{array}{l}\text { Taxa geom. } \\
\text { cresc. } \\
2000-2010\end{array}$ \\
\hline Itajaí & $<150 \mathrm{Km}$ & 2.848 & 11.283 & 14,76 & 10.609 & 33.549 & 12,20 \\
\hline Londrina & $<150 \mathrm{Km}$ & 4.844 & 11.093 & 8,64 & 24.371 & 38.573 & 4,70 \\
\hline S. J. do Rio Preto & $<150 \mathrm{Km}$ & 2.402 & 6.822 & 11,00 & 17.440 & 32.946 & 6,57 \\
\hline Total 1 & $<150 \mathrm{Km}$ & 10.094 & 29.198 & 11,21 & 52.420 & 105.068 & 7,20 \\
\hline Itajaí & $<75 \mathrm{Km}$ & 2.636 & 10.283 & 14,58 & 9.999 & 32.387 & 12,47 \\
\hline Londrina & $<75 \mathrm{Km}$ & 4.201 & 9.476 & 8,47 & 22.239 & 35.724 & 4,85 \\
\hline S. J. do Rio Preto & $<75 \mathrm{Km}$ & 1.881 & 4.631 & 9,43 & 15.297 & 29.072 & 6,63 \\
\hline Total 2 & $<75 \mathrm{Km}$ & 8.718 & 24.390 & 10,84 & 47.535 & 97.183 & 7,41 \\
\hline
\end{tabular}

Fonte: org. de IBGE, 2000; 2010a.

Nota-se claramente que a taxa geométrica de crescimento dos deslocamentos com origem nas cidades médias enfocadas é maior do que as de destino a elas. Diferenças marcantes, nesse sentido, podem ser observadas quanto a Londrina e a São José do Rio Preto. Esses dados corroboram a hipótese levantada em Reolon e Miyazaki (2015, p. 49), de que "o cenário urbano-regional, mesmo no interior do País, tem se tornado gradativamente mais complexo no que se refere aos deslocamentos entre municípios", com ocorrência de uma dispersão regional dos centros de atração de fluxos, implicando na configuração de 
multi e policentralidades ${ }^{5}$ que extrapolam os limites próprios das cidades (médias, no caso), reproduzindo-se na escala urbana regional. De modo complementar essa, Moura, Delgado e Costa (2013, p. 673) citam que

A magnitude do número de pessoas em deslocamento evidencia a importância da mobilidade para o acesso ao mercado de trabalho e aos serviços e funções de educação que se distribuem de forma dispersa/complementar entre municípios de uma mesma unidade regional - casos em que reforça e faz surgir centralidades e subcentralidades.

Dando seguimento às análises, outros dois indicadores foram utilizados para interpretação dos movimentos pendulares cotidianos da população, buscando-se compreender o papel exercido pelas cidades médias em âmbito regional.

\section{Índice de eficácia migratória}

O Índice de Eficácia Migratória, na análise dos movimentos pendulares, foi utilizado por Lima e Braga (2013) e por Moura, Delgado e Costa (2013). Conforme Lima e Braga (2013, p. 62), este consiste na razão entre o saldo migratório e o total de deslocamentos de destino e os de origem. Similar ao saldo dos deslocamentos de destino sobre os de origem, esse índice revela uma noção da capacidade de absorver ou repelir população em relação ao total de pessoas cujos movimentos envolveram a localidade. Resultados próximos de 1 indicam predomínio dos fluxos de entrada e próximos de - 1 indicam predomínio dos fluxos de saída, sendo zero o ponto de certo equilíbrio entre ambos. As Figuras 5 e 6 apresentam a distribuição espacial desses índices para os anos de 2000 e de 2010.

Constata-se que no caso das três cidades médias analisadas, embora os índices de eficácia migratória tenham se mantido positivos, reduziram-se entre 2000 e 2010, certificando a relativa ampliação dos fluxos de saída sobre os de entrada. As mudanças verificadas nos índices foram as seguintes: Itajaí (de 0,58 em 2000 para 0,50 em 2010); Londrina (de 0,67 para 0,55); e São José do Rio Preto (de 0,76 para 0,66).

5 Conforme Sposito (2007), a expressão poli(multi)centralidade foi adotada por Lefebvre em Revolução Urbana e adaptada para designar o aparecimento de novas áreas de concentração de estabelecimentos comerciais e de serviços nas cidades de porte médio. Para a autora, a multicentralidade designa a multiplicação de áreas centrais, enquanto a policentralidade é adotada para se referir à diversificação de padrões de bens e serviços ofertados, bem como de sua clientela. Neste caso específico, deve-se levar em conta que os movimentos pendulares representam deslocamentos para estudo e trabalho, e este pode ser executado inclusive na área industrial. Portanto, esse detalhe implica em que a hipótese referida possivelmente seja corroborada e reforçada, embora ainda não possa ser confirmada. 
Figura 5: Índice de eficácia migratória nas áreas de estudo em 2000.
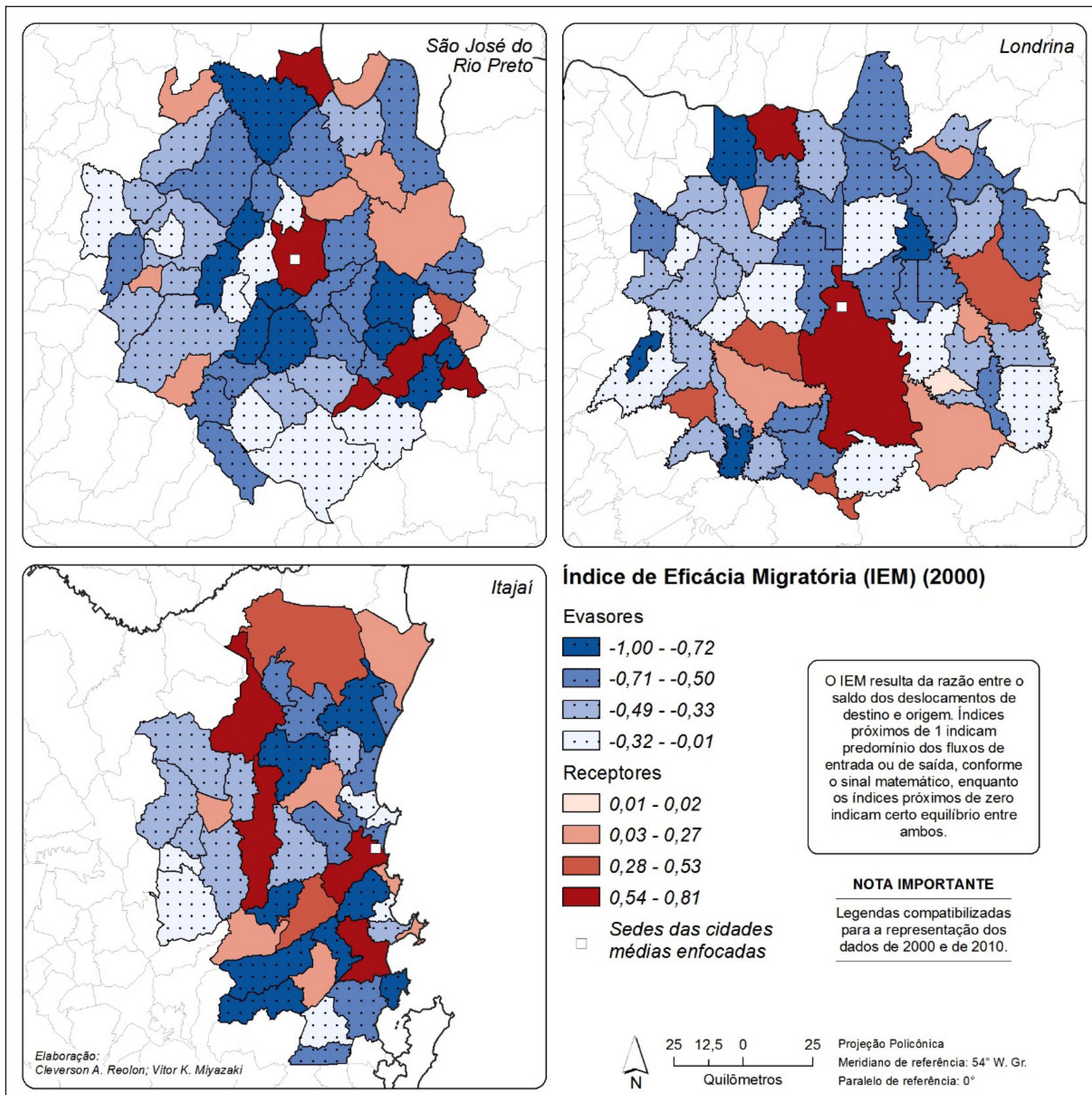

\section{Índice de Eficácia Migratória (IEM) (2000)}

\section{Evasores}

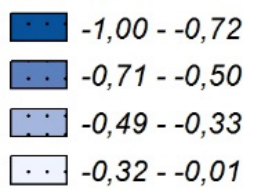

\section{Receptores}

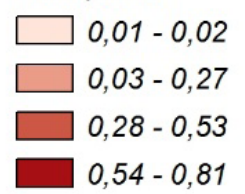

Sedes das cidades médias enfocadas

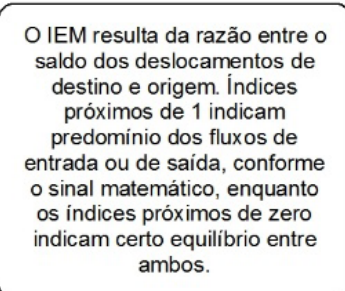

\section{NOTA IMPORTANTE}

Legendas compatibilizadas para a representação dos dados de 2000 e de 2010 .

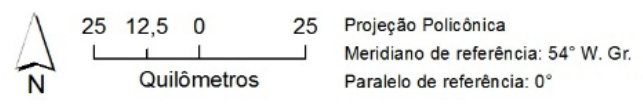

Bases cartográficas: IBGE, 2000; 2010a; 2010b. 
Figura 6: Índice de eficácia migratória nas áreas de estudo em 2010.

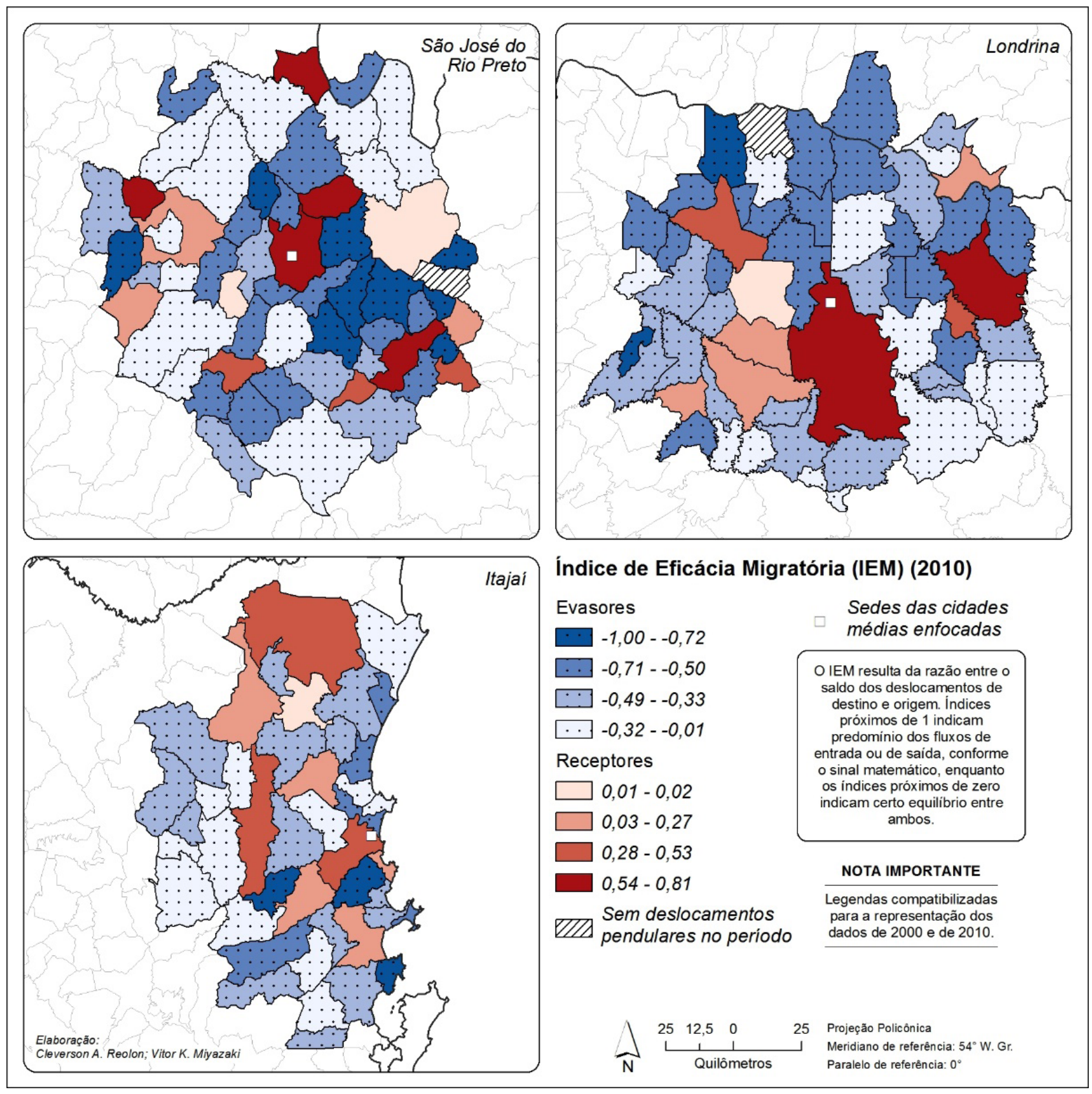

Bases cartográficas: IBGE 2000; 2010a; 2010b.

\section{Atração e repulsão populacional}

O mapeamento de um outro índice, capaz de revelar o grau de atração e de repulsão exercido numa determinada localidade também foi realizado (Figs. 7 e 8). Normalmente, o grau relativo de atração ou de repulsão consiste na razão entre as entradas e saídas somente com relação ao trabalho sobre a população residente ocupada (DESCHAMPS, 2009), ma para esta pesquisa também foram computados os deslocamentos para estudo, lembrando que os dados quantificam as pessoas que se deslocam e não os fluxos propriamente ditos. É preciso considerar ainda que, nesta pesquisa, este índice mediu o acréscimo proporcional de 
trabalhadores e de estudantes à quantidade da população de cada município que trabalha e/ ou que estuda. Deschamps (2009, p. 211) certifica que

Geralmente os municípios que apresentam altas taxas de atração são aqueles que sofrem pressão sobre as estruturas econômicas e de serviços, e os que apresentam altas taxas de repulsão sofrem pressão na esfera social, sinalizando com função de municípios-dormitórios.

Figura 7: Graus de atração e de repulsão nas áreas de estudo em 2000.
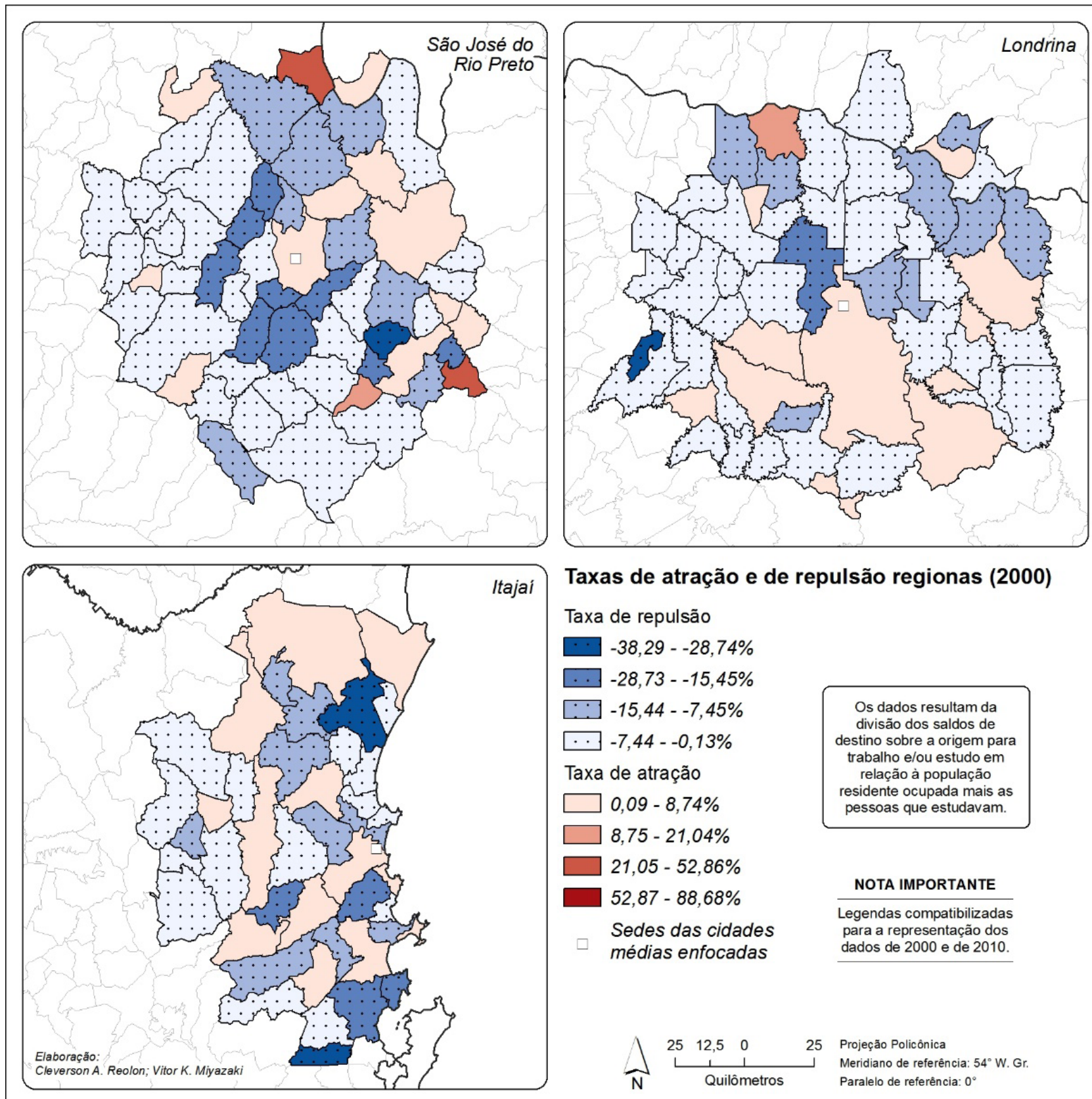

Taxas de atração e de repulsão regionas (2000)

Taxa de repulsão

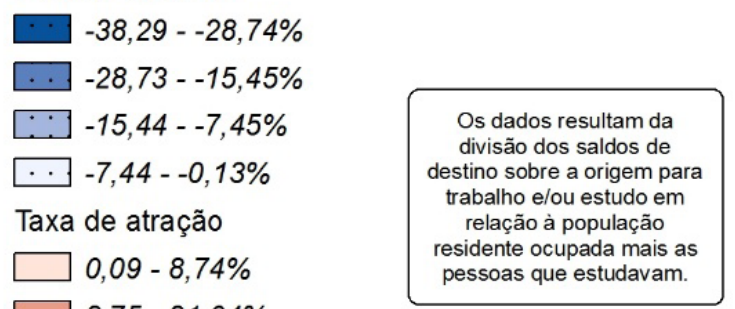

$8,75-21,04 \%$

$21,05-52,86 \%$

$52,87-88,68 \%$

Sedes das cidades

médias enfocadas

NOTA IMPORTANTE

Legendas compatibilizadas para a representação dos dados de 2000 e de 2010.

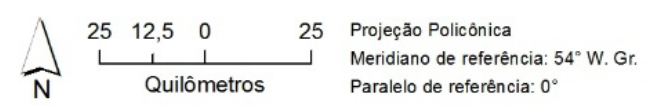

Bases cartográficas: IBGE, 2000; 2010a; 2010b. 
Figura 8: Graus de atração e de repulsão nas áreas de estudo em 2010.

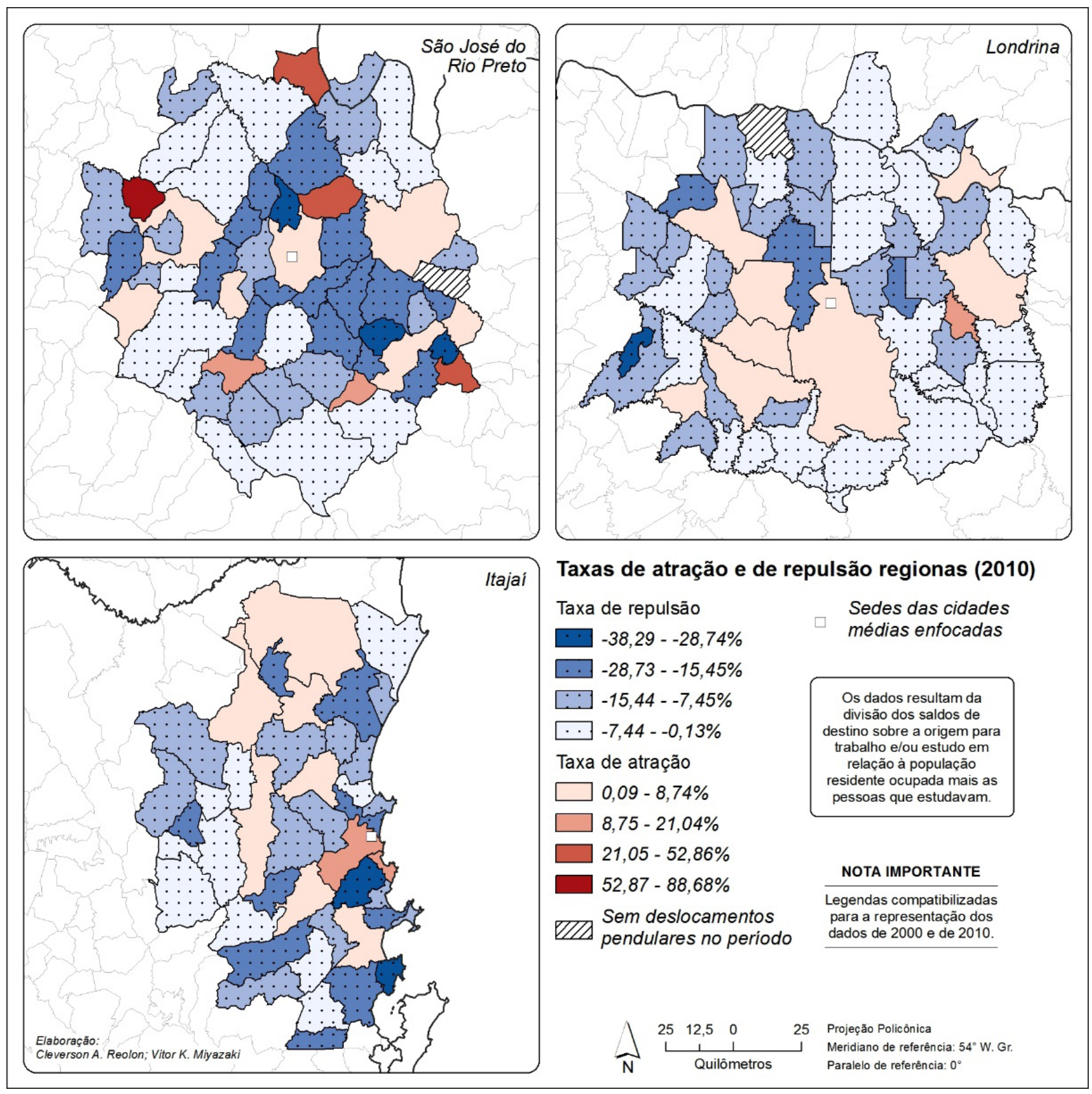

Bases cartográficas: IBGE, 2000; 2010a; 2010b.

Os graus de atração e de repulsão calculados revelam que a cidades médias enfocadas na pesquisa exercem atração sobre a população que reside nos municípios vizinhos, mas, à exceção de Itajaí, não são aquelas que apresentam os índices mais elevados. O grau de atração de Londrina inclusive se reduziu no período analisado, passando de 6,85 para 6,34\%, ao passo que os índices de Itajaí e de São José do Rio Preto se elevaram, respectivamente, de 7,75 para $14,27 \%$ e de 6,99 para $7,99 \%$. 


\section{CONSIDERAÇÕES FINAIS}

Não se pode dizer que as cidades médias enfocadas na pesquisa estão perdendo importância quanto ao seu papel em nível regional. A diminuição relativa dos deslocamentos pendulares realizados a partir dos municípios adjacentes com destino a essas cidades deve ser ponderada pela ampliação nominal das trocas. Além disso, os graus de atração e de repulsão indicam que ainda são atrativas sobre o entorno, não obstante essa atração ser relativamente baixa, provavelmente devido aos vetores de crescimento internos de cada município não terem se esgotado. Ou seja, ainda há possibilidade de novos moradores fixarem residência dentro dos limites dessas cidades médias - isso parece ser menos verdadeiro para o caso de Itajaí, onde a pressão sobre as estruturas econômicas e de serviços se ampliou bastante no interregno analisado.

Os mapeamentos dos fluxos de cada recorte territorial das cidades amostradas podem ser consultados em Reolon e Miyazaki (2015) e em Miyazaki e Reolon (2017). Tais mapeamentos evidenciam a ampliação dos fluxos de longa distância nas áreas que configuram os entornos das cidades médias aqui analisadas ${ }^{6}$ e também reforçam os resultados das análises implementadas nesta pesquisa ao demonstrarem que se ampliaram os fluxos entre os municípios adjacentes a estas cidades médias. Os resultados em questão sugerem um cenário urbano-regional multi e polinucleado do ponto de vista das centralidades, articulados espacialmente, embora do ponto de vista territorial os tecidos urbanos sejam descontínuos.

Em síntese, os resultados apontam para o fato de que a estrutura urbana regional está se tornando mais complexa, ampliando-se e consolidando-se os vínculos e interações espaciais regionais, com propensão à formação e consolidação de aglomerações urbanas polarizadas por cidades médias tendo em vista a ampliação dos movimentos pendulares de médias e longas distâncias (médias em relação aos centros regionais).

Entende-se, todavia, que os movimentos pendulares não são suficientes para avaliar a difusão das atividades e dos vetores de expansão das atividades comerciais e de serviços responsáveis pela promoção do consumo e, nesse sentido, entende-se haver necessidade de investigações adicionais mediante aplicação de inquéritos ou de entrevistas voltadas não apenas aos moradores das cidades médias, mas também às pessoas que residem nos municípios situados nas adjacências delas, objetivando-se averiguar hábitos de deslocamento para consumo de mercadorias ou de serviços. É bastante provável que se constate que a nova realidade urbana, na qual os deslocamentos pendulares intermunicipais já se tornaram cotidianos para a população, já não nos permita mais restringir as análises geográficas à escala cartográfica local, isto é, limitada aos perímetros municipais ou das cidades enfocadas em cada pesquisa.

6 Moura, Castello Branco e Firkowski (2005) já haviam feito essa constatação para o Brasil. 


\section{AGRADECIMENTOS}

Ao engenheiro agrônomo Anael Cintra, pelo auxílio fundamental na extração e processamento dos dados utilizados nesta pesquisa.

\section{REFERÊNCIAS}

DESCHAMPS, M.V. Análise dos movimentos pendulares nos municípios de Santa Catarina: uma abordagem regional. Revista Paranaense de Desenvolvimento, n.116, p.195-216, 2009.

IBGE - Instituto Brasileiro de Geografia e Estatística. Áreas urbanizadas do Brasil 2015: concentrações urbanas de 100.000 a 300.000 habitantes]. Rio de Janeiro: 2017a. Arquivo shapefile contendo os polígonos das áreas urbanizadas das Concentrações Urbanas com população de 100.000 mil a 300.000 habitantes.

IBGE - Instituto Brasileiro de Geografia e Estatística. Áreas urbanizadas do Brasil 2015: Rio de Janeiro: 2017b. Arquivo shapefile contendo os polígonos das áreas urbanizadas das Concentrações Urbanas com mais de 300.000 habitantes, mais as capitais estaduais Boa Vista (RR) e Palmas (TO) (2011-2015).

IBGE - Instituto Brasileiro de Geografia e Estatística. Arranjos populacionais e concentrações urbanas do Brasil. 2.ed. Rio de Janeiro, 2016. Contém base de dados Access com temas vetoriais utilizados no projeto do IBGE "Arranjos Populacionais e Concentrações Urbanas do Brasil".

IBGE - Instituto Brasileiro de Geografia e Estatística. Censo Demográfico 2000: microdados da amostra. Rio de Janeiro, 2000. Disponível em <http:/ / downloads.ibge.gov.br/downloads_estatisticas.htm>. Acesso em: 01 jul. 2014.

IBGE - Instituto Brasileiro de Geografia e Estatística. Censo Demográfico 2010: microdados da amostra. Rio de Janeiro: 2010a. Disponível em <http://downloads.ibge.gov.br/downloads_estatisticas.htm>. Acesso em: 01 jul. 2014.

IBGE - Instituto Brasileiro de Geografia e Estatística. Malha municipal digital do Brasil. Rio de Janeiro: 2010b. Projeção geográfica e policônica - 1:2.500.000. 1 CD-ROM.

IPEA; IBGE; UNICAMP. Caracterização e tendências da rede urbana do Brasil: configuração atual e tendências da rede urbana. Brasília: IPEA, 2002. v.. 1

IPEA; IBGE; UNICAMP. Caracterização e tendências da rede urbana do Brasil: estudos básicos para a caracterização da rede urbana. Brasília: IPEA, 2001. v. 2

LIMA, E.E.C. de; BRAGA, F.G. Da rotatividade migratória à baixa migração: uma análise dos padrões da mobilidade populacional no Brasil de 1995-2000. Revista Brasileira de Estudos de População, v.30, n.1, p. 57-75, jan./jun.2013.

MIYAZAKI, V.K. Estruturação da cidade e morfologia urbana: um estudo sobre cidades de porte médio da rede urbana paulista. Presidente Prudente, 2013. Tese (Doutorado em Geografia) - Universidade Estadual Paulista, UNESP.

MIYAZAKI, V.K.; REOLON, C.A. O processo de aglomeração urbana em cidades médias. In: OLIVEIRA, H.C.M. de; CALIXTO, M.J.M.S.; SOARES, B.R. (Org.). Cidades médias e região. São Paulo: Cultura Acadêmica, 2017. p. 139-173.

MOURA, R.; CASTELLO BRANCO, M.L.; FIRKOWSKI, O.L.C. de F. Movimento pendular e perspectivas de pesquisas em aglomerados urbanos. São Paulo em Perspectiva, v.19, n.4, p.121-133, 2005.

MOURA, R.; DELGADO, P.; COSTA, M.A. Movimento pendular e políticas públicas: algumas possibilidades inspiradas numa tipologia dos municípios brasileiros. In: BOUERI, R.; COSTA, M.A. (Ed.). Brasil em desenvolvimento 2013: estado, planejamento e políticas públicas. Brasília: IPEA, 2013. (Brasil: o estado de uma nação, 3). 
OJIMA, R. Pessoas, prédios eruas: por uma perspectiva demográfica dos processos urbanos contemporâneos. In:OJIMA, R.; MARANDOLA JUNIOR, E. (org.) Dispersão urbana e mobilidade populacional: implicações para o planejamento urbano e regional. São Paulo: Edgard Blucher, 2016.

REIS, N. Notas sobre urbanização dispersa e novas formas do tecido urbano. São Paulo: Via das Artes, 2006.

REOLON, C.A. A aglomeração urbana da soja: Cascavel e Toledo no contexto da metropolização na mesorregião oeste paranaense. Toledo, 2007. Dissertação (Mestrado em Desenvolvimento Regional e Agronegócio) - Universidade Estadual do Oeste do Paraná, UNIOESTE.

REOLON, C.A. Os espaços de comando do capital e de produção industrial no Brasil. Presidente Prudente, 2012. Tese (Doutorado em Geografia) - Universidade Estadual Paulista, UNESP.

REOLON, C.A. Produção industrial e comando do capital no Brasil. Uma análise espacial. São Paulo: Cultura Acadêmica, 2013.

REOLON, C.A.; MIYAZAKI, V.K. Cidades Médias: um viés pelos Deslocamentos Pendulares. Espaço Aberto, v. 5, n. 1, p. 49-71, 2015.

SMITH, N. Contornos de uma política espacializada: veículos dos sem teto e produção da escala geográfica. In: ARANTES, A.A. (org.). O espaço da diferença. Campinas: Papirus, 2000. p. 132-175.

SPOSITO, M.E.B. O chão em pedaços: urbanização, economia e cidades no Estado de São Paulo. Presidente Prudente, 2004. Tese (Livre Docência) - Universidade Estadual Paulista, UNESP.

SPOSITO, M.E.B. Reestruturação urbana e segregação socioespacial no interior paulista. Scripta Nova, v. 11, n. 245 (11), ago. 2007. Disponível em: http:/ / www.ub.edu/geocrit/sn/sn-24511.htm Acesso em 15 jun. 2017.

WHITACKER, A.M. Inovações tecnológicas, mudanças nos padrões locacionais e na configuração da centralidade em cidades médias. Scripta Nova, v.11, n. 245 (24), ago. 2007. Disponível em: http://www. ub.edu/geocrit/sn/sn-24524.htm Acesso em 15 jun. 2017.

Data de submissão: 23/fev./2019

Data de aceite: 01/ago./2019 